\title{
Design of Optimal Control Techniques for Diesel Engines in Automotive Systems
}

\author{
Ravichandra, Mahesh Rao K
}

\begin{abstract}
Improving the performance of the state variables associated in the dynamics of air path is a current challenge for the control system community. In the context of automotive systems, disturbance is one of the major factor to destabilize or reduce the performance of the system. Hence, in this paper experiments are performed when the system is subjected to deterministic \& random noises by designing the optimal Linear Quadratic Regulator (LQR) and Linear Quadratic Gaussian (LQG) controllers. The proposed controllers are implemented using MATLAB/SIMULINK @ platform and the results are compared.
\end{abstract}

Index Terms-LQR, Optimal Control, LQG, Kalman filter.

\section{INTRODUCTION}

Air path is used in the diesel engines because it provides a fresh air with necessary oxygen into the cylinders. For air path dynamics associated in automotive systems operating over range of operating conditions with disturbances, stabilizing the system, reducing the overshoots for state variables is quite a challenge. This has been an area of intense research for automotive industry in past few decades. Control system community has been using Exhaust Gas Recirculation (EGR), Variable Geometry Turbine (VGT) \& Fuelling has control inputs of air dynamics for this purpose. A brief literature survey of more recent works in this domain of research presented below is a good motivation for the proposed work.

(Mike Huang et al. 2016) proposed a model predictive control (MPC) for diesel air path dynamics and the results shows that Zero-offset steady state tracking is achieved. (Javad Mohammadpour \& Karolos Grigoriadis et al. 2010) presents the linear parameter varying (LPV) decoupling control and a prefilter to improve the tracking performance in the air path of Diesel engines modeled as a quasi-LPV system. Simulation results show significant improvement achieved by the proposed controller. The authors in (Stephan Zentner \& Erika et al. 2014), designed the control strategy to handle cross-couplings of the system and the results are compared with a conventional controller of equal tuning. For the comparison, a single-stage turbocharged diesel engine equipped with a VGT and HP EGR was used.

(Dezong Zhao, Cunjia Liu \& Richard Stobart et al. 2013) addresses the air path regulation in turbocharged diesel engines using an explicit model predictive control (EMPC) approach and simulation results significantly improves the tracking performance of the exhaust emission variables against the decentralized single-input single-output (SISO) control method. The transient feedforward control system in an automated way for the diesel engine was proposed by (Giorgio Mancini \& Jonas Asprion et al. 2014). Researchers implemented on a real engine and experimental results are presented along with the techniques and the development of the methodology.

(Fereidoon Shabaninia et al. 2012) introduces an optimal LQG/LTR control method for a gas turbine and the simulation results are compared with PID controller. The results reveals that the proposed controller has good performance. (Mohamed Guermouche \& Sofiane Ahmed Ali et al. 2014), developed a higher order sliding mode control technique for the internal combustion engine air path and the simulation results of air path engine model shows good results under actuator faults conditions even in the presence of parametric uncertainties. Authors compare (Peter Langthaler \& Luigi del Re et al.2014) different robust predictive control strategies applied to a Diesel engine airpath and the results conclude that the Robust Model Predictive Control (RMPC) technique provides more sophisticated strategy to the standard engine control strategies which are tuned by application engineers. (Zhijia Yang et al. 2014) explores innovative control structures design for a heavy duty Caterpillar C6.6 diesel engine and the simulation results reveal that the proposed control structure provides better performance for the system damping.

In summary, the literature survey of the recent works reveal that most of the researchers are not concentrating on comparing their control methods when the system is subjected to disturbances and also in today's highly complex automotive system improving the performance of a system with disturbance is quite a challenge. Hence, in order to overcome the above challenges, in the present work, deterministic and random noises are subjected to the air path dynamics and solved using LQG controller and the results are compared with LQR controller. 


\section{DYNAMICS OF DIESEL ENGINES}

The basic structure of the turbocharged diesel engine system is shown in Fig. 1. This model consists of control inputs such as EGR, VGT \& Fuelling.

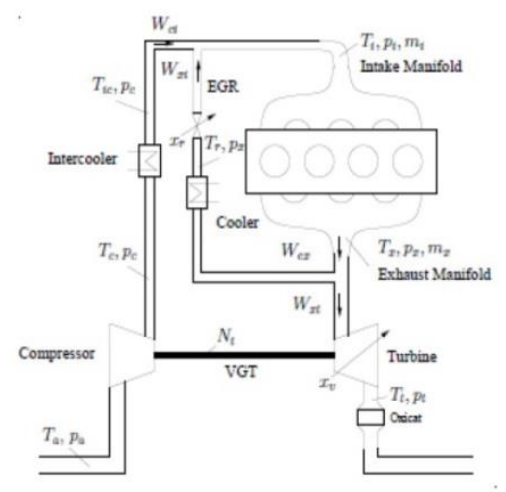

Figure 1: Structure of Turbocharged Diesel Engine

(Jung M et al. 2003) proposed the third order nonlinear model value parameters considering low and medium speed load points, which covers the New European Drive Cycle (NEDC) for robust control purposes. After, linearization the Linear Time Invariant (LTI) Model can be written in the state space as:

$$
\begin{aligned}
& \Delta \dot{x}=A \Delta x+B \Delta u \\
& \Delta y=C \Delta x+D \Delta u
\end{aligned}
$$

where, $\Delta x=x-x_{0}, \Delta u=u-u_{0}$, and $\Delta y=y-$ $y_{0} ; A, B, C, D$ are the coefficient matrices of the state space model. The Numerical values of $A \& B$ matrices used for the experiment is as follows (Jung M et al. 2003):

$$
\begin{gathered}
A=\left[\begin{array}{lll}
-5.2643 & 4.7316 & 28.5021 \\
50.7697 & -156.9827 & 0 \\
0 & 0.4287 & -9.0909
\end{array}\right] \\
B=\left[\begin{array}{lll}
1.6111 \times 10^{9} & 0 & 0 \\
-1.5720 \times 10^{1} 0 & 8.3514 \times 10^{4} & 1.46083 \times 10^{8} \\
0 & -141.6484 & 0
\end{array}\right]
\end{gathered}
$$

Table 1: States and Input/Output variables of the system

\begin{tabular}{|l|l|l|}
\hline \multicolumn{1}{|c|}{ Variable } & Notation & Function \\
\hline EGR-Actuator effective area & $\Delta A_{\text {egr }}$ & Input \\
\hline VGT-Actuator position & $\Delta x_{v g t}$ & Input \\
\hline Engine speed & $\Delta N$ & Disturbance \\
\hline
\end{tabular}

\begin{tabular}{|l|l|l|}
\hline $\begin{array}{l}\text { Intake manifold pressure } \\
\left(p_{i}\right)\end{array}$ & $\Delta x_{1}$ & \multicolumn{1}{|c|}{ State } \\
\hline $\begin{array}{l}\text { Exhaust manifold pressure } 1 \\
\left(p_{x}\right)\end{array}$ & $\Delta x_{2}$ & variable 2 \\
\hline Turbine power $\left(P_{c}\right)$ & $\Delta x_{3}$ & variable 3 \\
\hline
\end{tabular}

\section{OPTIMAL CONTROL THEORY}

The systematic way of finding a control law $\mathrm{u}=-\mathrm{Kx}$, where the closed system has a guarantee of stability with some optimization achieved between the control cost \& output performance is referred to as optimal control. For the current research, the optimized feedback controllers are derived from the LQR and when the system is subjected to disturbances, the controllers are derived from LQG. For, the sake of completeness LQR \& LQG control methods are explained briefly in the following sections:

\section{A. Linear Quadratic Regulator Control}

The performance index can be minimized by desigining the feedback controlers with the standard tool of LQR (Anderson et al., 2007); Yathisha et al., 2013).

Consider a system with

$$
\begin{gathered}
x^{\cdot}(t)=A x(t)+B u(t) \\
y(t)=C x(t)
\end{gathered}
$$

The input $\mathrm{u}(\mathrm{t})$ is expressed as $\mathrm{r}(\mathrm{t})-\mathrm{Kx}(\mathrm{t})$, where $\mathrm{f}(\mathrm{t})$ is the reference input and $\mathrm{K}$ is the feedback gain, also colyed the control law.

The closed loop system is given by

$$
x^{*}(t)=(A-B K) x(t)
$$

The most systematic and popular method to find $\mathrm{K}$ is to minimize the quadratic performance index

$$
\mathrm{J}=\int_{0}^{\infty}\left(\mathrm{x}^{\wedge} \mathrm{T} \mathrm{Qx}+\mathrm{u}^{\wedge} \mathrm{T} \mathrm{Ru}\right) \mathrm{dt}
$$

Where $\mathrm{Q}$ and $\mathrm{R}$ are the positive-definite Hermitian or real symmetric matrix.

From the above equations

$$
\mathrm{K}=-\mathrm{R}^{\wedge}(-1) \mathrm{B}^{\wedge} \mathrm{T} P
$$

and hence the control law is

$$
u(t)=-K x(t)=-R^{\wedge}(-1) B^{\wedge} T \operatorname{Px}(t)
$$

in which P must satisfy reduced Riccati equation:

$$
\mathrm{PA}+\mathrm{A}^{\wedge} \mathrm{T} \mathrm{P}-\mathrm{PBR}^{\wedge}(-1)+\mathrm{B}^{\wedge} \mathrm{T} \mathrm{P}+\mathrm{Q}=0
$$

The LQR function allows you to choose two parameters, $R$ and $\mathrm{Q}$, which will balance the relative importance of the input 
and state in the cost function that you are trying to optimize.

\section{B. Linear Quadratic Gaussian Control}

If a controller is designed using the LQR, and the observer is designed using Kalman filter, the resulting system is referred to as LQG Control.

The Kalman filter method provides the procedure for designing observer gains for Multi Input- Multi Output (MIMO) systems, such that the designed observer gain is guaranteed to be optimal even in the presence of noise signal. Consider a plant with LTI state space representation given as

$$
\begin{gathered}
x^{\prime}(t)=A x(t)+B u(t)+w(t) \\
y(t)=C x(t)+D u(t)+v(t)
\end{gathered}
$$

Where, $\mathrm{w}(\mathrm{t})$ is the process noise and $\mathrm{v}(\mathrm{t})$ is the measurement noise.

$$
\mathrm{u}(\mathrm{t})=-\mathrm{Kx}(\mathrm{t})
$$

The Kalman filter is an optimal estimator when dealing with Gaussian white noise. Specifically, it minimizes the asymptotic covariance of the estimation error $\mathrm{e}_{-} 0=\mathrm{x}-\mathrm{x} \hat{\text {, given }}$ by

$$
\lim _{-}(t \rightarrow \infty) E\left((x-x)(x-x)^{\prime}\right)
$$

The goal is to regulate the plant output y to be near zero. The state equation of the Kalman filter can be written as (Azad et al., 2013; Tripathy et al., 2010):

$$
\dot{\hat{x}}=A \hat{x}+B u+L(y-C \hat{x}-D u)
$$

For the time invariant problem, the following algebraic Riccati equation provides the optimal covariance matrix $M$, (Yousef et al., 2008):

$$
A M+M A^{T}-M C^{T} V^{-1} C M+B W B^{T}=0 .
$$

The algebraic Riccati equation can be solved using the specified Kalman filter MATLAB command lqe (linear quadratic estimator). The Kalman filter optimal gain $L$ is given by

$$
[L, M, E]=\operatorname{lqe}(A, B, C, W, V)
$$

where

$L$ is the returned Kalman filter optimal gain, equation and

$M$ is the returned solution to the algebraic Riccati

$E$ is a vector containing the eigenvalues of the Kalman filter (eigenvalues of $A-L C$ ).

Finally, combining the separately designed optimal LQR $(K)$ regulator and Kalman filter into an optimal compensator (LQG) as shown in Fig. 2, the new subsystem generates the input vector, $u(t)$ based upon the estimated state vector, $\hat{x}(t)$, rather than the actual state vector $x(t)$ and the measured output $y(t)$.

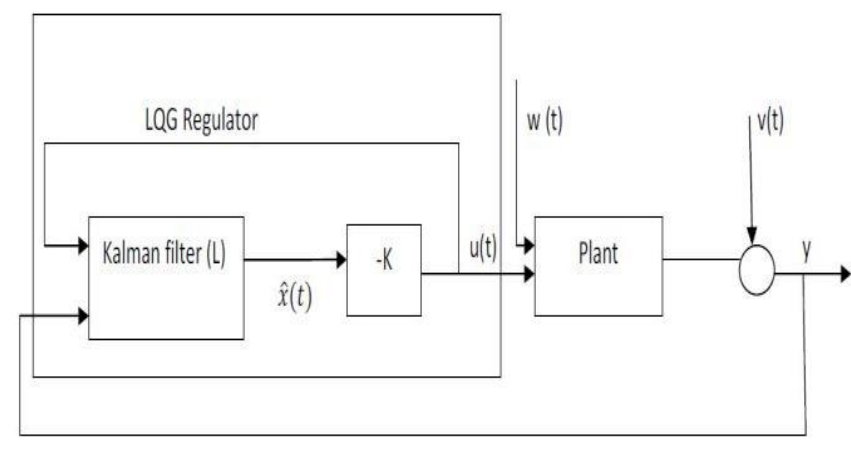

Figure 2: Block Diagram of Optimal LQG compensator

\section{EXPERIMENTAL SET-UP}

The proposed novel control techniques for the control inputs VGT $\left(B_{2}\right)$ \& Fuelling $\left(B_{3}\right)$ is investigated by considering the following cases:

Case I: LQR \& LQG Controllers are designed for the control input VGT $\left(B_{2}\right)$. The feedback controller and observer gains for the state variables Intake manifold pressure $\left(p_{i}\right)$ and Turbine power $\left(p_{x}\right)$ deviations are as follows:

$$
\begin{gathered}
K\left(p_{i}\right)=\left[\begin{array}{lll}
0.9886 & 0.0089 & 0.0644
\end{array}\right] \\
K\left(p_{x}\right)=\left[\begin{array}{lll}
0.0026 & 0.0026 & 0.7668
\end{array}\right] \\
L\left(p_{i}\right)=\left[\begin{array}{lll}
1.207 \times 10^{5} & 1.5555 \times 10^{9} & -2.6337 \times 10^{6}
\end{array}\right] \\
L\left(p_{x}\right)=\left[\begin{array}{lll}
5.5416 \times 10^{7} & -3.4898 \times 10^{8} & 2.6451 \times 10^{6}
\end{array}\right]
\end{gathered}
$$

Case II: LQR \& LQG Controllers are designed for the control input Fuelling $\left(B_{3}\right)$. The feedback controller and observer gains for the state variables Intake manifold pressure $\left(p_{i}\right)$ and Turbine power $\left(p_{x}\right)$ deviations are as follows:

$$
\begin{gathered}
K\left(p_{i}\right)=\left[\begin{array}{lll}
0.99997 & 2.5343 \times 10^{-4} & 0.0015
\end{array}\right] \\
K\left(p_{x}\right)=\left[\begin{array}{lll}
3.4753 * \times 10^{-7} & 7.5482 \times 10^{-5} & 0.9984
\end{array}\right] \\
L\left(p_{i}\right)=\left[\begin{array}{lll}
2.125 \times 10^{8} & 4.7718 \times 10^{15} & 1.9253 \times 10^{7}
\end{array}\right] \\
L\left(p_{x}\right)=\left[\begin{array}{lll}
7.0597 \times 10^{8} & 4.7718 \times 10^{15} & 6.3964 \times 10^{7}
\end{array}\right]
\end{gathered}
$$

The $K\left(p_{i}\right) \& K\left(p_{x}\right)$ are the feedback controller gains calulated from the optimal LQR control theory using the algebraic riccati equation in (9) by tuning the weighting matrices as $Q=I \& R=1$. Similarly, $L\left(p_{i}\right) \& L\left(p_{x}\right)$ are the observer gains calculated from the optimal LQG in equation (15)

\section{SIMULATION RESULTS}

The dynamic responses of the state variables Intake manifold $\left(p_{i}\right)$ and Turbine power $\left(p_{x}\right)$ for the two control inputs VGT $\left(B_{2}\right) \&$ Fuelling $\left(B_{3}\right)$ for all the cases are shown in Fig's 3-6. 


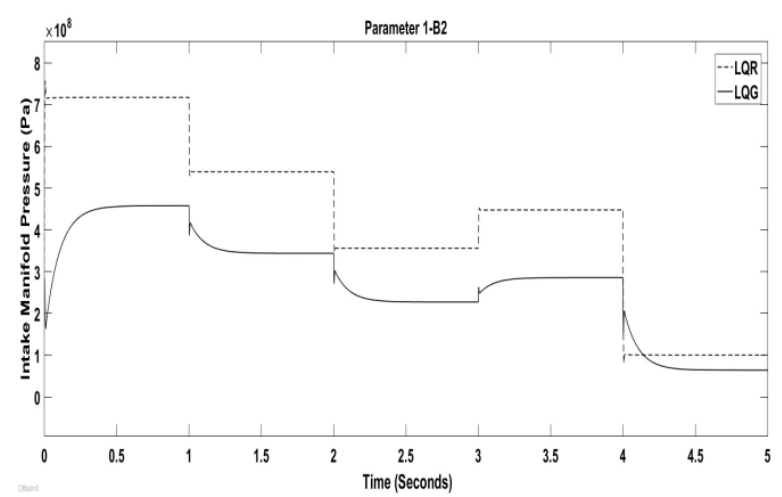

Figure 3: $p_{i}$ response of Case I

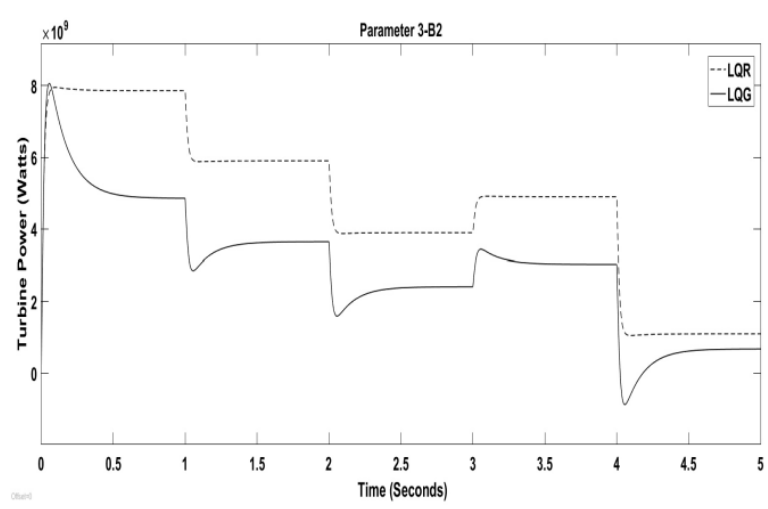

Figure $4: p_{x}$ response of Case I

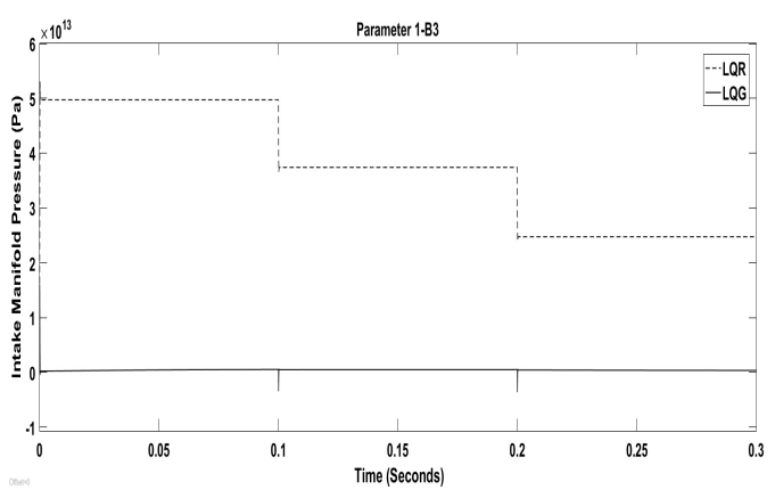

Figure 5: $p_{i}$ response of Case II

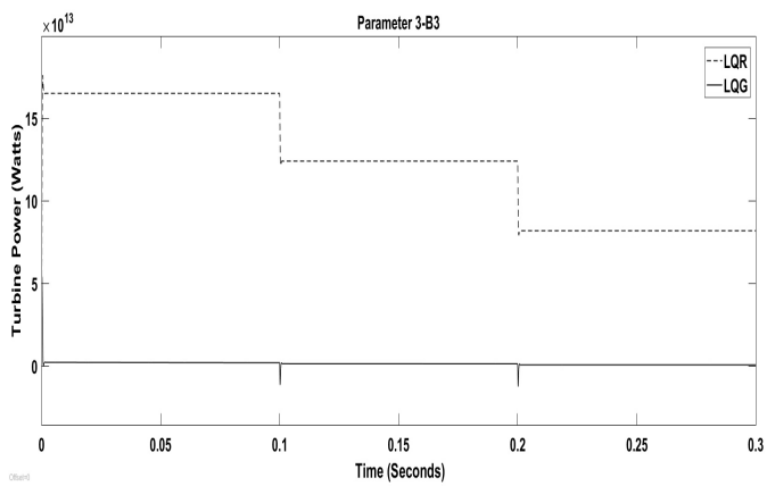

Figure 6: $p_{x}$ response of Case II

The simulation results of case I (Fig. $3 \&$ Fig. 4) and Case II (Fig. 5 \& Fig. 6) shows the response of the two state variables $\left(p_{i} \& p_{x}\right)$ under the deterministic and random disturbances for the control inputs VGT $\left(B_{2}\right)$ \& Fuelling $\left(B_{3}\right)$. The deterministic disturbance is calulated as in LQG control design and the random disturbance is distributed with random signal with output repeatable for a given speed with mean $=$ 0 ; variance $=4$, speed $=0.5 \&$ sampling time $=0.1 \mathrm{sec}$.

The simulation results reveals that the LQG control shows the improved performance with respect to damping and steady state errors compared to the LQR control techniques.

\section{Conclusion}

In the context of automotive system disturbance is one of the factors to destabilize or to reduce the performance of the system and also in today's highly complex automotive system improving the performance of a system with disturbance is quite a challenge. Hence, In order to overcome the above challenges, in this paper the control techniques are designed and experimented when the system is subjected to deterministic \& random noises to the air path dynamics and solved by designing the optimal controllers using Linear Quadratic Gaussian (LQG). Two set of experiments are carried to show the effectiveness of the proposed control techniques. The Optimal LQR \& LQG controllers are designed by considering the disturbances for the state variables $p_{i} \& p_{x}$ of air path dynamics for the two control inputs $B_{2} \& B_{3}$ and the simulation results reveals that LQG controllers are better compared to LQR controllers when the system is subjected to disturbances.

\section{REFERENCES}

[1] Mike Huang, "Low Complexity Model Predictive Control of a Diesel Engine Airpath", Ph.D. Thesis, Aerospace Engineering, University of Michigan, 2016.

[2] Javad Mohammadpour, Karolos Grigoriadis \& Matthew Franchek, "LPV Decoupling and Input Shaping for Control of Diesel Engines, Proceedings of American Control Conference, June 30-July 02, 2010, pp. 1477-1482.

[3] Stephan Zentner, Erika Schafer, Gerald Fast, Christopher H Onder and Lino Guzzella, "A cascaded control structure for airpath control of diesel engines", Journal of Automobile Engineering, Vol. 228, Issue 7, 2014, pp. 799-817, DOI:10.1177/0954407013493617.

[4] Dezong Zhao, Cunjia Liu \& Richard Stobart, "Explicit Model Predictive Control on the Air Path of Turbocharged Diesel Engines", Proceedings of IEEE American Automatic Control Council, Loughborough University, 2013.

[5] Giorgio Mancini , Jonas Asprion \& NicolÃ² Cavina, "Dynamic Feedforward Control of a Diesel Engine Based on Optimal Transient Compensation Maps", Energies, Vol. 7, pp. 5400-5424, ISSN: 1996-1073, DOI:10.3390/en70854

[6] Fereidoon Shabaninia \& Kazem Jafari, "Using LQG/LTR Optimal Control Method to Improve Stability and Performance of Industrial Gas Turbine System", International Scholarly Research Network ISRN Electronics, Vol.1, 2012 ,pp. 1-8, DOI:10.5402/2012/134580.

[7] Mohamed Guermouche \& Sofiane Ahmed Ali "Sliding mode control for variable geometry turbocharged diesel engines", American Control Conference, Vol. 1, Issue 6, pp. 584-588, 2014, DOI 10.1109/ACC.2000.878967.

[8] Peter Langthaler \& Luigi del Re, "Predictive Control of a Diesel Engine Air Path", IEEE Transactions on Control Systems Technology, Vol. 15, Issue 3, 2014, pp. 449 - 456, DOI: 10.1109/TCST.2007.894638.

[9] Zhijia Yang, "Optimal Air and Fuel-Path Control of a Diesel Engine", Ph.D. Thesis, Department of Aeronautical and Automotive Engineering Loughborough University November 2014.

[10] Jung M, "Mean-value modelling and robust control of the air path of a turbocharged diesel engineâ€•, Ph.D Dissertation, University of 


\section{Available online at www.ijrat.org}

Cambridge, 2003.

[11] B. D. O. Anderson, J. B. Moore, “Optimal Control: Linear Quadratic Methods", New York: Dover Publications, 2007.

[12] L. Yathisha \& S. P. Kulkarni, "Optimum LQR switching approach for the improvement of STATCOM performance", Proceedings of the Third International Conference on Trends in Information, Telecommunication and Computing, New York: Springer, 2013, pp $259-266$.

[13] S. P. Azad \& R. Iravani, T. J. E, "Damping inter-area oscillations based on a model predictive control (MPC) HVDC supplementary controller", IEEE Transactions on Power Systems, 2013, Vol. 28, Issue 3, pp. $3174-3183$.

[14] P. Tripathy, S. C. Srivastava \& S. N. Singh, "A divide-by-differencefilter based algorithm for estimation of generator rotor angle utilizing synchrophasor measurements", IEEE Transactions on Instrumentation and Measurement, 2010, Vol. 59, Issue 6, pp. 1562-1570.

[15] A. M. Yousef \& M. Zahran, "Improved power system stabilizer by

\section{AUTHORS PROFILE}

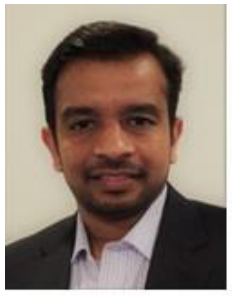

Dr Ravichandra has 7+ years of teaching and research experience, he is an enthusiastic academician and has taken the academic profession by choice. He has done his $\mathrm{PhD}$ in Engineering from AUT, Auckland NZ and has a stint of industrial experience post-PhD. He is currently working as Associate Professor in the Department of ECE, Maharaja Institute of Technology Mysore. His research interests pan across a lot of interdisciplinary areas right from Engineering pedagogy, Engineering materials to Embedded Artificial Intelligence. applying LQG controller", Advances in Electrical and Computer Engineering, 2008, Vol. 8, Issue 1, pp. 117 -127.

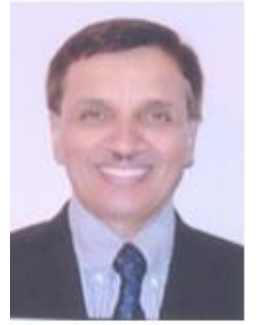

Dr Mahesh Rao got his BE in Electronics and Communication, First class with Distinction, from Sri Jayachamarajendra College of Engineering, University of Mysore in 1981 and then went on to do his Masters in Applied Science, Electrical Engineering from University Of Windsor, Canada in 1984. Then completed his $\mathrm{PhD}$ from University of Wyoming, Laramie in 1988 in Electrical Engineering specializing in 3-D actuator design and control for Robots.

He worked as Assistant Professor for five years at University of Reno, Nevada (1987 to 1992) and then Joined Intel as Technical Support Manager in 1992 (Sacramento USA). Then he became Validation Manager for Intel Chipsets and the Program Manager for Integrated Microprocessors. He was recognized with Intel Achievement Award for his contributions to the Chipset development. In 2000 he returned to India as General Manager for Intel Bangalore.He then started his own Company, Aspire Communication in 2002 at Mysore which employed more than 600 engineers by 2011. Currently he is Professor and Head, Dept of ECE, MIT Mysore. 